\title{
Fatores de risco associados à alta contagem de células somáticas do leite do tanque em rebanhos leiteiros da Zona da Mata de Minas Gerais
}

\author{
[Risk factors associated with high bulk milk somatic cell count in dairy herds from \\ Zona da Mata of Minas Gerais, Brazil]

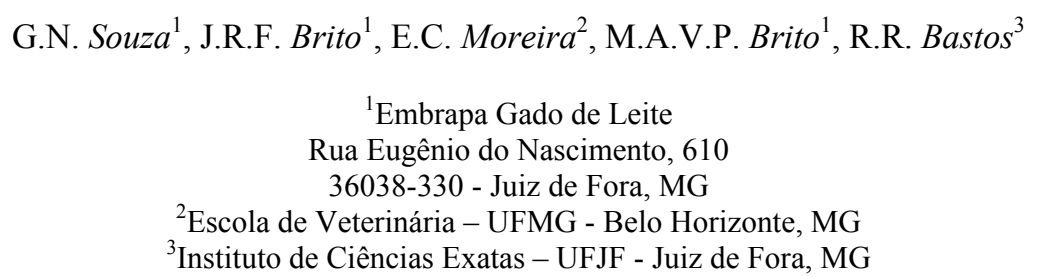

\section{RESUMO}

Características do rebanho e práticas de manejo associadas à contagem de células somáticas do leite do tanque (CCSLT) foram estudadas em 175 rebanhos envolvidos em programas de acompanhamento entre junho de 2000 e dezembro de 2001. Os dados foram obtidos por meio de aplicação de questionários. Os rebanhos foram classificados em dois grupos de acordo com a média geométrica de seis CCSLT mensais, consecutivas, tendo como referência o valor de 500.000 células $/ \mathrm{ml}$. Os métodos estatísticos utilizados foram a análise exploratória dos dados e os modelos logísticos de regressão. Procedimentos relacionados ao controle e à prevenção de mastite foram adotados por pequeno número de rebanhos. $\mathrm{O}$ tipo de ordenha (manual, mecânica canalizada e balde-ao-pé), a idade média dos rebanhos, o local de ordenha e a realização de exames dos primeiros jatos de leite não foram associados à alta CCSLT. Os fatores associados à alta CCSLT foram a não adoção de linha de ordenha, a alimentação durante a ordenha e a ausência de anti-sepsia dos tetos após a ordenha.

Palavras-chave: bovino, mastite, fator de risco, leite do tanque, célula somática

\begin{abstract}
ABSCTRACT
Herd features and management practices associated with high bulk milk somatic cell count (BMSCC) were studied in 175 dairy herds enrolled on BMSCC programs. Herds data were obtained from June/2000 to December/2001 by questionnaires application. Herds were classified according to the geometric mean of six consecutive BMSCC records. Exploratory analysis and logistic regression models were the statistical analysis applied. Procedures about mastitis control and prevention were adopted in a few herds. Type of milking (machine or hand milking), herd age, milking place (milking parlour, pen, corral) and strip test practice (first streams of milk) were not associated with high BMSCC. Factors associated with high BMSCC were the following: do not milk clinical mastitic cows at the end of milking, feeding cows at milking and absence of post milking teat disinfection.
\end{abstract}

Keywords: bovine, mastitis, risk factors, bulk milk, milk somatic cell

Recebido para publicação em 28 de abril de 2004

Recebido para publicação, após modificações, em 20 de agosto de 2004

E-mail: gnsouza@cnpgl.embrapa.br 


\section{INTRODUÇÃO}

Fatores de risco relacionados ao animal, ao meio ambiente e aos procedimentos de manejo são associados à saúde da glândula mamária em rebanhos leiteiros. Exemplos de fatores relacionados ao animal identificados como de risco para mastite são: número de parições, estádio da lactação (início e final), alta produção e escape de leite no momento da ordenha (Omore et al., 1996; Peeler et al., 2000). Fatores associados ao manejo e características como tamanho do rebanho e tipo de ordenha (manual ou mecânica) e procedimentos durante a ordenha (não desinfecção das tetas antes e após a ordenha) foram associados à ocorrência de novas infecções intramamárias e ao aumento da contagem de células somáticas (CCS) (Oliver et al., 1993; Brito et al., 1998). Funcionamento inadequado do equipamento de ordenha, não treinamento e motivação dos ordenhadores foram associados à ocorrência de novas infecções e, conseqüentemente, ao aumento da CCS do leite do tanque (CCSLT; Spencer, 2002; Cavazos, 2003).

A CCSLT é uma medida indireta do percentual de quartos mamários infectados no rebanho, obedecendo à relação diretamente proporcional entre a contagem de células somáticas e o número de quartos mamários infectados no rebanho (Philpot e Nickerson, 1991). A utilização de areia na cama das vacas em lactação ao invés de matéria orgânica, as boas condições higiênicas do estábulo, a imersão das tetas em solução desinfetante após a ordenha, o tratamento à secagem, o tratamento imediato dos casos clínicos com antimicrobianos, o descarte de animais-problema e a segregação de animais infectados no momento da ordenha, bem como a utilização de unidades de ordenha específicas para esses animais, foram identificados como fatores que reduzem a CCSLT (Hueston et al., 1990; Wilson et al., 1997; Barkema et al., 1998; Berry e Hillerton, 2002).

Estudos sobre fatores de risco para a mastite e seu impacto econômico foram realizados em países de pecuária leiteira desenvolvida. Neles, a maioria dos rebanhos é composta por animais de alta produção, criados em sistemas de confinamento total ou parcial (Schukken et al., 1989; Wilson et al., 1997; Barkema et al., 1999; Ott e Novak, 2001).
No Brasil, parte significativa dos rebanhos leiteiros é constituída por animais mestiços, criados em pasto ou semi-estabulados. Em geral, há carência de trabalhos de avaliação dos fatores de risco para mastite. Este estudo teve como objetivo identificar e quantificar fatores relacionados às características de rebanho, procedimentos de manejo durante a ordenha $\mathrm{e}$ higienização do equipamento de ordenha que influenciam na CCSLT.

\section{MATERIAL E MÉTODOS}

O trabalho foi conduzido em 175 rebanhos da bacia leiteira da Zona da Mata de Minas Gerais, no período de junho de 2000 a dezembro de 2001. Foi aplicado um questionário aos responsáveis pelos rebanhos para obter informações sobre propriedade e composição do rebanho (tempo na atividade, número de vacas em lactação, número de vacas secas, número de vacas de acordo com a ordem de lactação, produção total de leite/dia, formas de exploração, local de ordenha, tipo de ordenha, raça do rebanho), sobre manejo e cuidados higiênicos durante a ordenha e procedimentos com vistas ao controle e à prevenção de mastites (linha de ordenha, exame dos primeiros jatos, lavagem e secagem dos tetos antes da ordenha, forma de secagem dos tetos, desinfecção dos tetos antes e após a ordenha, fornecimento de alimento durante a ordenha, imersão do conjunto de teteiras entre a ordenha de cada vaca, tratamento à secagem, tratamento de casos clínicos) e sobre características e higienização da ordenhadeira mecânica (disponibilidade de água quente na sala de ordenha, utilização de detergentes alcalino, ácido e sanitizante na limpeza do equipamento, manutenção da ordenhadeira, hábitos higiênicos dos ordenhadores, treinamento dos ordenhadores e idade do equipamento de ordenha). Os rebanhos foram classificados de acordo com a média geométrica dos resultados de seis CCSLT consecutivas, correspondendo a um período máximo de seis meses e pelo menos uma análise mensal. As seis análises utilizadas para composição da média geométrica foram as três últimas e as três primeiras em relação à data de aplicação do questionário. $\mathrm{O}$ valor de referência para classificação dos rebanhos foi 500.000 células $/ \mathrm{ml}$. As análises para identificação dos fatores de risco foram realizadas considerando as seguintes situações: todos os rebanhos $(n=175)$, 
rebanhos com ordenha mecânica $(n=82)$, rebanhos com ordenha manual $(\mathrm{n}=92)$ e rebanhos com média geométrica menor que 250.000 células $/ \mathrm{ml} \quad(\mathrm{n}=37)$ e maior que 750.000 células $/ \mathrm{ml}(\mathrm{n}=38)$, classificados de acordo com a análise de conglomerados, com base na média geométrica da CCSLT.

Foram realizadas análises bivariadas para testar associações entre cada variável independente. $\mathrm{O}$ teste $\mathrm{t}$ foi usado para variáveis contínuas, e o teste qui-quadrado para variáveis categóricas. $\mathrm{O}$ critério de decisão para a escolha dos fatores de risco foram aqueles que ofereciam explicação biológica coerente na alteração da CCSLT e que na associação apresentaram $\mathrm{P}<0,20$ (Agger et al., 1994). Após a seleção das possíveis variáveis independentes, foi aplicada uma série de modelos de regressão logística, tendo como variável dependente (resposta) a classificação dos rebanhos de acordo com a CCSLT e, como variáveis independentes (explicativas), fatores anteriormente selecionados e relacionados às características do rebanho, às práticas de manejo durante a ordenha e à higienização do equipamento de ordenha. Após a seleção do modelo final de regressão logística, foram observados os coeficientes (odds ratio (OR) estimadores do risco relativo) de cada variável independente para se estimar o grau de risco (Frankena e Graat, 1997). O número máximo de variáveis independentes usadas nos modelos foi calculado em função do número de rebanhos pertencentes a cada classe de CCSLT, de acordo com as situações citadas anteriormente. As variáveis contínuas, número de vacas em lactação, produção diária do rebanho (litros/dia) e percentual do rebanho no período seco foram categorizadas, pois apresentaram grande variação em relação às médias e facilitaram a interpretação dos coeficientes, caso eles fossem significativos nos modelos de regressão logística. Os limites das categorias foram determinados de forma que não houvesse diferenças acentuadas em termos de número de rebanhos em cada categoria. As análises estatísticas foram realizadas utilizando-se o programa estatístico SPSS versão 8.0 (Statistical..., 1998).

\section{RESULTADOS E DISCUSSÃO}

Dos 175 rebanhos incluídos no estudo, 92 $(52,6 \%)$ utilizaram ordenha manual e 82 $(46,9 \%)$, ordenha mecânica. Os rebanhos rejeitados para as análises foram os que apresentaram informações insuficientes (Tab. 1).

Tabela 1. Rebanhos selecionados, rejeitados e utilizados no modelo final de regressão logística de acordo com a situação estudada - Zona da Mata, Minas Gerais

\begin{tabular}{|c|c|c|c|c|c|c|c|c|}
\hline \multirow{2}{*}{ Rebanho } & \multicolumn{2}{|c|}{1} & \multicolumn{2}{|c|}{2} & \multicolumn{2}{|c|}{3} & \multicolumn{2}{|c|}{4} \\
\hline & $\mathrm{n}$ & $\%$ & $\mathrm{n}$ & $\%$ & $\mathrm{n}$ & $\%$ & $\mathrm{n}$ & $\%$ \\
\hline Selecionados & 175 & 100,0 & 82 & 100,0 & 92 & 100,0 & 79 & 100,0 \\
\hline RADAD & 22 & 12,6 & 11 & 13,4 & 4 & 4,3 & 4 & 5,0 \\
\hline RIAMG $\leq 500$ & 75 & 49,0 & 40 & 56,3 & 38 & 43,2 & - & - \\
\hline RIAMG $>500$ & 78 & 51,0 & 31 & 43,7 & 50 & 56,8 & - & - \\
\hline RIAMG $\leq 250$ & - & - & - & - & - & - & 37 & 49,3 \\
\hline RIAMG $\geq 750$ & - & - & - & - & - & - & 38 & 50,7 \\
\hline
\end{tabular}

RADAD $=$ rebanhos rejeitados na análise devido à ausência de dados; RIAMG $\leq 500=$ rebanhos incluídos na análise com média geométrica da CCSLT $\leq 500.000$ células/ml ${ }^{1}$; RIAMG $>500$ = rebanhos incluídos na análise com média geométrica da CCSLT $>500.000$ células $/ \mathrm{ml}$; RIAMG $\leq 250$ = rebanhos incluídos na análise com média geométrica da CCSLT $\leq 250.000$ células/ml; RIAMG $\geq 750$ = rebanhos incluídos na análise com média geométrica da CCSLT $\geq 750.000$ células $/$ ml; situação: $1=$ todos rebanhos, 2 = rebanhos com ordenha mecânica, 3 = rebanhos com ordenha manual, 4 = rebanhos classificados por análise de conglomerados, de acordo com a CCSLT

$\mathrm{Na}$ maioria dos rebanhos, os proprietários estavam há mais de 10 anos na atividade (Tab. 2), e os rebanhos eram formados por animais mestiços (Holandês $\times$ Gir com diferentes graus de sangue). O principal sistema de exploração foi o semi-estabulado, seguido pelos sistemas de produção em pasto e de confinamento total (free-stall). Aproximadamente metade das propriedades adotavam a ordenha manual. Entre as de ordenha mecânica, o número das que utilizavam ordenha canalizada era maior do que as de ordenha mecânica balde-ao-pé. 
Tabela 2. Freqüência das variáveis qualitativas e quantitativas categorizadas obtidas em rebanhos bovinos leiteiros - Zona da Mata, Minas Gerais

\begin{tabular}{|c|c|c|c|c|c|}
\hline Variável & Categoria & $n^{1}$ & $\%{ }^{2}$ & $<500.000^{3}$ & $>500.000^{3}$ \\
\hline \multirow{3}{*}{ Tempo na atividade (anos) } & $\leq 10$ & 64 & 36,6 & 35 & 29 \\
\hline & 11 a 20 & 43 & 24,6 & 18 & 25 \\
\hline & $>20$ & 66 & 37,7 & 36 & 30 \\
\hline \multirow{3}{*}{ Sistema } & Confinado (free stall) & 14 & 8,0 & 8 & 6 \\
\hline & Em pasto & 51 & 29,1 & 30 & 21 \\
\hline & Semi-estabulado & 110 & 62,9 & 51 & 59 \\
\hline \multirow{3}{*}{ Tipo de ordenha } & Manual & 92 & 52,6 & 41 & 51 \\
\hline & Mecânica balde-ao-pé & 36 & 20,6 & 22 & 14 \\
\hline & Mecânica canalizada & 46 & 26,3 & 25 & 21 \\
\hline \multirow{2}{*}{ Local de ordenha } & Curral & 133 & 76,0 & 70 & 63 \\
\hline & Sala de ordenha & 39 & 22,3 & 16 & 23 \\
\hline \multirow{3}{*}{ Vacas em lactação (\%) } & $\leq 30$ & 66 & 37,7 & 38 & 28 \\
\hline & 31 a 60 & 43 & 24,6 & 18 & 25 \\
\hline & $>60$ & 64 & 36,6 & 32 & 32 \\
\hline \multirow{3}{*}{ Vacas até a $3^{\mathrm{a}}$ lactação (\%) } & 0 a 59 & 23 & 13,1 & 8 & 15 \\
\hline & 60 a 79 & 66 & 37,7 & 40 & 26 \\
\hline & 80 a 100 & 77 & 44,0 & 35 & 42 \\
\hline \multirow{3}{*}{ Vacas secas $(\%)$} & $\leq 20$ & 38 & 21,7 & 22 & 16 \\
\hline & 21 a 50 & 120 & 68,6 & 60 & 60 \\
\hline & $>50$ & 15 & 8,6 & 7 & 8 \\
\hline \multirow{3}{*}{ Produção leite/dia (litros) } & $\leq 300$ & 73 & 41,7 & 43 & 30 \\
\hline & 301 a 500 & 25 & 14,3 & 15 & 10 \\
\hline & $>500$ & 73 & 41,7 & 30 & 43 \\
\hline \multirow{2}{*}{ Raça } & Holandesa & 34 & 19,4 & 17 & 17 \\
\hline & Mestiço & 140 & 80,0 & 72 & 68 \\
\hline
\end{tabular}

${ }^{1}$ Soma total diferente de 175 por falta de resposta para a variável no questionário; ${ }^{2}$ soma total diferente de 100 por falta de resposta para a variável; ${ }^{3} \times 10^{3}$ células $/ \mathrm{ml}$.

Noventa e quatro propriedades $(53,7 \%)$ dispunham da sala de ordenha.Em $80,0 \%$ e $74,9 \%$ dos rebanhos havia, no mínimo, $60,0 \%$ de vacas até a terceira lactação e mais de 50,0\% delas no período seco, respectivamente.

O tratamento dos casos clínicos de mastite foi o único procedimento realizado em praticamente todos os rebanhos (Tab. 3). A adoção dos demais procedimentos relacionados ao controle variou de $27,4 \%$ (tratamento à secagem) a $65,1 \%$ (segregação dos animais com mastite clínica).

Procedimentos e cuidados higiênicos ligados à prevenção de novas infecções mostraram que essas medidas não estavam bem difundidas, com exceção do tratamento dos casos clínicos. Procedimentos como lavagem dos tetos antes da ordenha e secagem com papel toalha individual e tratamento à secagem de todos os animais influenciam, de modo favorável, na freqüência e no controle de mastite do rebanho (Oliver et al., 1993; Brito et al., 1998). A escolha de animais que serão tratados à secagem e a utilização de pano comum para secagem dos tetos após lavagem e/ou anti-sepsia antes da ordenha foram procedimentos inadequados identificados. Sabese que o tratamento à secagem de somente parte do rebanho favorece o aparecimento de novas infecções intramamárias durante o período seco e no momento do parto (Berry e Hillerton, 2002).

Em 53,0\% das propriedades, os equipamentos de ordenha tinham, no máximo, quatro anos de uso e, em menos de $10,0 \%$, mais de 10 anos de uso (Tab. 4), indicando que nos últimos anos houve aumento na aquisição de equipamentos de ordenha. Em decorrência disso, as propriedades passaram a necessitar de assistência técnica especializada e adotaram procedimentos de rotina relacionados à higienização do equipamento. 
Fatores de risco associados à alta contagem de células somáticas...

Tabela 3. Freqüências das variáveis qualitativas e quantitativas relacionadas aos procedimentos de manejo e cuidados higiênicos durante a ordenha de rebanhos bovinos leiteiros - Zona da Mata, Minas Gerais

\begin{tabular}{lccccc}
\hline Variável & Categoria & $\mathrm{n}^{1}$ & $\%^{2}$ & $<500.000^{3}$ & $>500.000^{3}$ \\
\hline Linha de ordenha & Não & 59 & 33,7 & 31 & 28 \\
& Sim & 114 & 65,1 & 58 & 56 \\
Exame dos primeiros jatos & Não & 128 & 73,1 & 69 & 59 \\
& Sim & 45 & 25,7 & 19 & 26 \\
\hline Presença de bezerro & Não & 60 & 34,3 & 30 & 30 \\
& Sim & 101 & 57,7 & 51 & 50 \\
\hline Lavagem dos tetos antes da ordenha & Não & 92 & 52,6 & 44 & 48 \\
& Sim & 81 & 46,3 & 45 & 36 \\
\hline Secagem dos tetos após a lavagem & Não & 68 & 38,9 & 33 & 35 \\
& Sim & 81 & 46,3 & 45 & 36 \\
Processo de secagem dos tetos após a lavagem & Pano comum & 22 & 12,6 & 12 & 10 \\
& Papel toalha & 48 & 27,4 & 25 & 23 \\
Anti-sepsia dos tetos antes da ordenha & Não & 123 & 70,3 & 65 & 58 \\
\hline \multirow{2}{*}{ Alimentação durante a ordenha } & Sim & 51 & 29,1 & 23 & 28 \\
\hline Anti-sepsia dos tetos após a ordenha & Não & 104 & 59,4 & 59 & 45 \\
\hline Imersão das teteiras em solução & Sim & 67 & 39,3 & 28 & 39 \\
entre ordenhas de animais & Não & 121 & 69,1 & 62 & 59 \\
\hline Tratamento à secagem & Sim & 54 & 30,9 & 27 & 27 \\
\hline Tramento de mastite clínica & Não & 61 & 74,4 & 35 & 26 \\
\hline
\end{tabular}

${ }^{1}$ Soma total diferente de 175 por falta de resposta para a variável no questionário; ${ }^{2}$ soma total diferente de 100 por falta de resposta para a variável; ${ }^{3} \times 10^{3}$ células $/ \mathrm{ml}$.

Observou-se que $34,1 \%$ das propriedades não faziam manutenção dos equipamentos ou a faziam de forma esporádica e que $68,3 \%$ dispunham de água quente e de dispositivo para limpeza automática do equipamento.

Treinamento para limpeza do equipamento de ordenha e hábitos higiênicos adequados foram descritos em $84,1 \%$ e $86,6 \%$ das propriedades, respectivamente. $\mathrm{O}$ funcionamento inadequado do equipamento de ordenha, a falta de treinamento e a motivação do pessoal responsável pela operação e higienização do equipamento e a não realização de procedimentos recomendados em programas de controle e prevenção interagem e influenciam na freqüência de mastite no rebanho e, conseqüentemente, na CCSLT (Spencer, 2002; Brito, et al., 2002; Cavazos, 2003).
A freqüência das variáveis usadas nos modelos finais bem como a média dos valores de CCSLT para cada variável são apresentadas nas Tab. 5, 6, 7 e 8 . O nível de significância dos modelos finais de regressão logística para as situações estudadas foi $\mathrm{P}<0,05$. As variáveis usadas nos modelos finais que apresentaram risco (OR) acima de 2,0 e com $\mathrm{P} \leq 0,10$ foram: não antisepsia dos tetos após a ordenha, fornecimento de alimento no momento da ordenha, não adoção de linha de ordenha e interações de não adoção de linha de ordenha e não anti-sepsia dos tetos após a ordenha com fornecimento de alimento no momento da ordenha. A não desinfecção dos tetos antes da ordenha e o não uso de água quente ou o não treinamento dos ordenhadores apresentaram OR de 7,62 (P=0,17) e 2,97 $(\mathrm{P}=0,17)$, respectivamente (Tab. 9). 
Nos modelos finais, o sistema de ordenha em rebanhos com até $79 \%$ dos animais nas três primeiras lactações não foi fator de risco para CCSLT acima de 500.000 células $/ \mathrm{ml}$. Os principais fatores de risco identificados para CCSLT acima de 500.000 células $/ \mathrm{ml}$ foram: ausência de anti-sepsia dos tetos antes e após ordenha e não adoção de linha de ordenha. As interações que sugeriram possíveis fatores de risco para CCSLT acima de 500.000 células $/ \mathrm{ml}$ foram as que ocorreram entre a não realização de anti-sepsia dos tetos após a ordenha, a não adoção de linha de ordenha com fornecimento de alimento durante a ordenha e a não higienização do equipamento de ordenha (ausência de água quente e/ou treinamento dos ordenhadores). Apesar de a ausência de anti-sepsia dos tetos antes da ordenha e de a interação entre fatores relacionados à higienização terem apresentado OR de 7,62 e 2,93, respectivamente $(\mathrm{P}=0,17)$, esses podem ser considerados possíveis fatores de risco devido a um alto valor encontrado para OR. Os fatores de risco que elevaram a CCSLT de 250.000 para 750.000 células $/ \mathrm{ml}$ foram o fornecimento de alimento durante a ordenha e a não adoção de linha de ordenha.
O número de animais em lactação, utilizado nos modelos finais como variável contínua, aumentou o nível de significância dos modelos e exacerbou os valores da OR e respectivas significâncias, sugerindo que o tamanho do rebanho foi importante característica para análise de risco.

As interações fornecimento de alimento durante a ordenha versus não adoção de linha de ordenha e fornecimento de alimento durante a ordenha versus não adoção de anti-sepsia dos tetos após a ordenha foram os possíveis fatores de risco testados nos modelos que apresentaram maiores níveis de significâncias para OR. Dessa forma, sugere-se que, para identificação e quantificação de possíveis fatores de risco em modelos de regressão logística, tendo como referência a CCSLT, seria necessária a criação de uma variável originada do agrupamento de duas ou mais variáveis. A nova variável, analisada como fator de risco, poderia ser uma solução para direcionar procedimentos de forma geral, mas não permitiria identificar qual o procedimento, de forma isolada que mais contribui para $o$ aumento da CCSLT.

Tabela 4. Freqüências das variáveis qualitativas relacionadas aos procedimentos de higienização e idade do equipamento de ordenha de rebanhos bovinos leiteiros - Zona da Mata, Minas Gerais

\begin{tabular}{|c|c|c|c|c|c|}
\hline Variável & Categoria & $\mathrm{n}^{1}$ & $\%^{2}$ & $<500.000^{3}$ & $>500.000^{3}$ \\
\hline \multirow{3}{*}{ Idade do equipamento de ordenha (anos) } & $<=4$ & 47 & 57,3 & 30 & 17 \\
\hline & 5 a 10 & 24 & 29,3 & 12 & 12 \\
\hline & $>10$ & 8 & 9,8 & 3 & 5 \\
\hline \multirow{3}{*}{ Manutenção do equipamento de ordenha } & Pelo menos semestral & 46 & 56,1 & 26 & 20 \\
\hline & Esporádico & 12 & 14,6 & 8 & 4 \\
\hline & Não faz & 16 & 19,5 & 31 & 25 \\
\hline \multirow{2}{*}{ Disponibilidade de água quente } & Não & 26 & 31,7 & 16 & 10 \\
\hline & Sim & 56 & 68,3 & 31 & 25 \\
\hline \multirow{2}{*}{ Uso de detergente alcalino } & Não & 2 & 2,4 & 1 & 1 \\
\hline & Sim & 77 & 93,9 & 46 & 31 \\
\hline \multirow{2}{*}{ Uso de detergente ácido } & Não & 4 & 4,9 & 2 & 2 \\
\hline & Sim & 70 & 85,4 & 42 & 28 \\
\hline \multirow{2}{*}{ Uso de sanitizante } & Não & 7 & 8,5 & 5 & 2 \\
\hline & Sim & 50 & 61,0 & 27 & 23 \\
\hline \multirow{2}{*}{ Limpeza do equipamento de ordenha } & Automático & 56 & 68,3 & 32 & 24 \\
\hline & Manual & 26 & 31,7 & 15 & 11 \\
\hline \multirow{2}{*}{ Treinamento dos ordenhadores } & Não & 13 & 15,9 & 6 & 7 \\
\hline & Sim & 69 & 84,1 & 41 & 28 \\
\hline \multirow{2}{*}{ Hábitos higiênicos dos ordenhadores } & Inadequado & 10 & 12,2 & 6 & 4 \\
\hline & Adequado & 71 & 86,6 & 41 & 30 \\
\hline
\end{tabular}


Fatores de risco associados à alta contagem de células somáticas...

Tabela 5. Freqüências e médias da CCSLT de acordo com as variáveis utilizadas no modelo final de regressão logística para análise de rebanhos bovinos leiteiros - Zona da Mata, Minas Gerais

\begin{tabular}{|c|c|c|c|c|c|c|}
\hline \multirow{2}{*}{$\begin{array}{l}\text { Variável no modelo final } \\
\text { de regressão logística }\end{array}$} & \multicolumn{2}{|c|}{$<500.000^{1}$} & \multicolumn{2}{|c|}{$>500.000^{1}$} & \multirow{2}{*}{$\begin{array}{c}\text { Total } \\
\mathrm{n}\end{array}$} & \multirow[t]{2}{*}{ Média* } \\
\hline & $\mathrm{n}$ & $\%$ & $\mathrm{n}$ & $\%$ & & \\
\hline \multicolumn{7}{|l|}{ Tipo de ordenha } \\
\hline Mecânica canalizada & 25 & 54,3 & 21 & 45,7 & 46 & 600 \\
\hline Mecânica balde-ao-pé & 22 & 68,8 & 14 & 43,8 & 36 & 535 \\
\hline Manual & 41 & 44,6 & 51 & 55,4 & 92 & 523 \\
\hline \multicolumn{7}{|l|}{ Vacas em lactação (\%) } \\
\hline 0 a 59 & 8 & 34,8 & 15 & 65,2 & 23 & 599 \\
\hline 60 a 79 & 40 & 60,6 & 26 & 39,4 & 66 & 522 \\
\hline 80 a 100 & 35 & 45,5 & 42 & 54,5 & 77 & 551 \\
\hline \multicolumn{7}{|l|}{ Local de ordenha } \\
\hline Curral & 70 & 52,6 & 63 & 47,4 & 133 & 550 \\
\hline Sala de ordenha & 16 & 41,0 & 23 & 59,0 & 39 & 543 \\
\hline \multicolumn{7}{|l|}{ Exame dos primeiros jatos } \\
\hline Sim & 19 & 42,2 & 26 & 57,8 & 45 & 564 \\
\hline Não & 69 & 53,9 & 59 & 46,1 & 128 & 538 \\
\hline \multicolumn{7}{|c|}{ Anti-sepsia das tetas antes da ordenha } \\
\hline Sim & 23 & 45,1 & 28 & 54,9 & 51 & 582 \\
\hline Não & 65 & 52,8 & 58 & 47,2 & 123 & 530 \\
\hline \multicolumn{7}{|c|}{ Anti-sepsia das tetas após a ordenha } \\
\hline Sim & 27 & 50,0 & 27 & 50,0 & 54 & 558 \\
\hline Não & 62 & 51,2 & 59 & 48,8 & 121 & 538 \\
\hline \multicolumn{7}{|c|}{ Linha $\mathrm{x}$ fornecimento de alimento** } \\
\hline Sim & 40 & 59,7 & 27 & 40,3 & 67 & 474 \\
\hline Não & 47 & 46,1 & 55 & 53,9 & 102 & 585 \\
\hline
\end{tabular}

*Média aritmética; **linha de ordenha e alimentação durante a ordenha. CCSLT = contagem de células somáticas de leite do tanque. Vacas em lactação até a $3^{\mathrm{a}}$ parição. ${ }^{1} \times 10^{3}$ células $/ \mathrm{ml}$.

Tabela 6. Freqüências e médias da CCSLT de acordo com as variáveis utilizadas no modelo final de regressão logística para rebanhos bovinos leiteiros com equipamento de ordenha - Zona da Mata, Minas Gerais

\begin{tabular}{|c|c|c|c|c|c|c|}
\hline \multirow{2}{*}{$\begin{array}{l}\text { Variável no modelo final } \\
\text { de regressão logística }\end{array}$} & \multicolumn{2}{|c|}{$<500.000^{1}$} & \multicolumn{2}{|c|}{$<500.000^{1}$} & \multirow{2}{*}{$\begin{array}{c}\text { Total } \\
\mathrm{n}\end{array}$} & \multirow[t]{2}{*}{ Média* } \\
\hline & $\mathrm{n}$ & $\%$ & $\mathrm{n}$ & $\%$ & & \\
\hline \multicolumn{7}{|l|}{ Tipo de ordenha } \\
\hline Mecânica canalizada & 25 & 54,3 & 21 & 45,7 & 46 & 601 \\
\hline Mecânica balde-ao-pé & 22 & 61,1 & 14 & 38,9 & 36 & 535 \\
\hline \multicolumn{7}{|l|}{ Vacas em lactação (\%) } \\
\hline 0 a 59 & 5 & 50,0 & 5 & 50,0 & 10 & 613 \\
\hline 60 a 79 & 22 & 61,1 & 14 & 38,9 & 36 & 590 \\
\hline 80 a 100 & 15 & 51,7 & 14 & 48,3 & 29 & 563 \\
\hline \multicolumn{7}{|l|}{ Exame dos primeiros jatos } \\
\hline Sim & 6 & 50,0 & 6 & 50,0 & 12 & 592 \\
\hline Não & 40 & 58,8 & 28 & 41,2 & 68 & 572 \\
\hline \multicolumn{7}{|l|}{ Anti-sepsia das tetas após a ordenha $\times$ fornecimento de alimento** } \\
\hline $\operatorname{Sim}$ & 10 & 83,3 & 2 & 16,7 & 12 & 534 \\
\hline Não & 36 & 52,9 & 32 & 47,1 & 68 & 583 \\
\hline \multicolumn{7}{|l|}{ Higiene*** } \\
\hline Sim & 27 & 61,4 & 17 & 38,6 & 44 & 523 \\
\hline Falta de água quente ou não treinamento do ordenhador & 14 & 63,6 & 8 & 36,4 & 22 & 599 \\
\hline Falta de mais de um item & 6 & 37,5 & 10 & 62,5 & 16 & 669 \\
\hline
\end{tabular}




\section{Souza et al.}

Tabela 7. Freqüências e médias da CCSLT de acordo com as variáveis utilizadas no modelo final de regressão logística para rebanhos bovinos leiteiros com ordenha manual - Zona da Mata, Minas Gerais

\begin{tabular}{|c|c|c|c|c|c|c|}
\hline \multirow{2}{*}{$\begin{array}{l}\text { Variável no modelo final } \\
\text { de regressão logística }\end{array}$} & \multicolumn{2}{|c|}{$<500.000^{1}$} & \multicolumn{2}{|c|}{$>500.000^{1}$} & \multirow{2}{*}{$\frac{\text { Total }}{\mathrm{n}}$} & \multirow[t]{2}{*}{ Média* } \\
\hline & $\mathrm{n}$ & $\%$ & $\mathrm{n}$ & $\%$ & & \\
\hline \multicolumn{7}{|l|}{ Vacas em lactação (\%) } \\
\hline 0 a 59 & 2 & 16,7 & 10 & 83,3 & 12 & 626 \\
\hline 60 a 79 & 18 & 60,0 & 12 & 40,0 & 30 & 440 \\
\hline 80 a 100 & 20 & 41,7 & 28 & 58,3 & 48 & 543 \\
\hline \multicolumn{7}{|l|}{ Local de ordenha } \\
\hline Curral & 29 & 48,3 & 31 & 51,7 & 60 & 501 \\
\hline Sala de ordenha & 12 & 37,5 & 20 & 62,5 & 32 & 564 \\
\hline \multicolumn{7}{|l|}{ Exame dos primeiros jatos } \\
\hline Sim & 12 & 37,5 & 20 & 62,5 & 32 & 567 \\
\hline Não & 29 & 48,3 & 31 & 51,7 & 60 & 500 \\
\hline \multicolumn{7}{|c|}{ Anti-sepsia dos tetos antes da ordenha } \\
\hline Sim & 13 & 40,6 & 19 & 59,4 & 32 & 572 \\
\hline Não & 27 & 45,8 & 32 & 54,2 & 59 & 500 \\
\hline \multicolumn{7}{|c|}{ Anti-sepsia dos tetos após a ordenha } \\
\hline Sim & 14 & 40,0 & 21 & 60,0 & 35 & 572 \\
\hline Não & 27 & 47,4 & 30 & 52,6 & 57 & 494 \\
\hline
\end{tabular}

*Média aritmética. CCSLT $=$ contagem de células somáticas de leite do tanque. Vacas em lactação até a $3^{\mathrm{a}}$ parição. ${ }^{1} \mathrm{x} 10^{3}$ células $/ \mathrm{ml}$.

Tabela 8. Freqüências e médias da CCSLT de acordo com as variáveis utilizadas no modelo final de regressão logística para rebanhos bovinos leiteiros classificados de acordo com análise de cluster - Zona da Mata, Minas Gerais

\begin{tabular}{|c|c|c|c|c|c|c|}
\hline \multirow{2}{*}{$\begin{array}{l}\text { Variável no modelo final } \\
\text { de regressão logística }\end{array}$} & \multicolumn{2}{|c|}{$<250.000^{1}$} & \multicolumn{2}{|c|}{$>750.000^{1}$} & \multirow{2}{*}{$\begin{array}{c}\text { Total } \\
\mathrm{n} \\
\end{array}$} & \multirow[t]{2}{*}{ Média* } \\
\hline & $\mathrm{n}$ & $\%$ & $\mathrm{n}$ & $\%$ & & \\
\hline \multicolumn{7}{|l|}{ Tipo de ordenha } \\
\hline Mecânica canalizada & 4 & 26,7 & 11 & 73,3 & 15 & 884 \\
\hline Mecânica balde-ao-pé & 5 & 41,7 & 7 & 58,3 & 12 & 676 \\
\hline Manual & 28 & 45,9 & 23 & 37,7 & 61 & 516 \\
\hline \multicolumn{7}{|l|}{$\%$ vacas lactação 1,2 e 3} \\
\hline 0 a $59 \%$ & 4 & 50,0 & 4 & 50,0 & 8 & 642 \\
\hline 60 a $79 \%$ & 18 & 54,5 & 15 & 45,5 & 33 & 596 \\
\hline 80 a $100 \%$ & 16 & 43,2 & 21 & 56,8 & 37 & 596 \\
\hline \multicolumn{7}{|c|}{ Anti-sepsia das tetas após a ordenha } \\
\hline Sim & 4 & 25,0 & 12 & 75,0 & 16 & 758 \\
\hline Não & 34 & 54,0 & 29 & 46,0 & 63 & 567 \\
\hline \multicolumn{7}{|c|}{ Fornecimento de alimento durante ordenha } \\
\hline Sim & 15 & 42,9 & 20 & 57,1 & 35 & 652 \\
\hline Não & 23 & 52,3 & 21 & 47,7 & 44 & 569 \\
\hline \multicolumn{7}{|l|}{ Linha de ordenha } \\
\hline Sim & 33 & 55,9 & 26 & 44,1 & 59 & 545 \\
\hline Não & 5 & 27,8 & 13 & 72,2 & 18 & 757 \\
\hline
\end{tabular}


Tabela 9. Nível de significância dos modelos finais de regressão logística, valores de odds ratio e nível de significância para variáveis utilizadas nos modelos de acordo com as situações estudadas

\begin{tabular}{|c|c|c|c|c|c|c|c|c|}
\hline Modelo final de regressão logística & \multicolumn{8}{|c|}{ Situação ${ }^{1}$} \\
\hline & \multicolumn{2}{|c|}{1} & \multicolumn{2}{|c|}{2} & \multicolumn{2}{|c|}{3} & \multicolumn{2}{|c|}{4} \\
\hline Graus de liberdade & \multicolumn{2}{|c|}{10} & \multicolumn{2}{|c|}{8} & \multicolumn{2}{|c|}{7} & \multicolumn{2}{|c|}{7} \\
\hline Nível de significância (P) & \multicolumn{2}{|c|}{0,0007} & \multicolumn{2}{|c|}{0,0242} & \multicolumn{2}{|c|}{0,0338} & \multicolumn{2}{|c|}{0,0010} \\
\hline Possíveis fatores de risco & OR & $\mathrm{P}$ & OR & $\mathrm{P}$ & OR & $\mathrm{P}$ & OR & $\mathrm{P}$ \\
\hline Ordenha mecânica balde-ao-pé & 1,66 & 0,35 & 0,62 & 0,47 & - & - & 0,12 & 0,01 \\
\hline Ordenha manual & 0,47 & 0,19 & - & - & - & - & 0,06 & 0,02 \\
\hline Vacas em lactação (60 a 79\%) & 1,71 & 0,35 & 3,31 & 0,20 & 2,78 & 0,22 & 0,51 & 0,55 \\
\hline Vacas em lactação (80 a 100\%) & 0,30 & 0,00 & 0,64 & 0,47 & 0,28 & 0,02 & 0,21 & 0,03 \\
\hline Curral como local de ordenha & 0,52 & 0,20 & - & - & 0,32 & 0,08 & - & - \\
\hline Não realiza exame dos primeiros jatos & 0,64 & 0,49 & 0,29 & 0,24 & 0,48 & 0,40 & - & - \\
\hline Não realiza anti-sepsia antes da ordenha & 0,46 & 0,27 & - & - & 7,62 & 0,17 & - & - \\
\hline Não realiza anti-sepsia após a ordenha & 3,00 & 0,10 & - & - & 0,29 & 0,33 & - & - \\
\hline Fornece alimento durante a ordenha & - & - & - & - & - & - & 2,68 & 0,09 \\
\hline Não realiza linha de ordenha & - & - & - & - & - & - & 6,75 & 0,06 \\
\hline $\begin{array}{l}\text { Não realiza linha de ordenha e/ou fornece alimento } \\
\text { durante a ordenha }\end{array}$ & 2,33 & 0,03 & - & - & - & - & - & - \\
\hline $\begin{array}{l}\text { Não realiza anti-sepsia após a ordenha e/ou fornece } \\
\text { alimento durante a ordenha }\end{array}$ & - & - & 7,57 & 0,06 & - & - & - & - \\
\hline $\begin{array}{l}\text { Ausência de água quente ou não treinamento do } \\
\text { ordenhador }\end{array}$ & - & - & 2,97 & 0,17 & - & - & - & - \\
\hline Ausência de mais de um item relacionado à higiene* & - & - & 1,50 & 0,55 & - & - & - & - \\
\hline Número de vacas em lactação** & 1,00 & 0,03 & 1,01 & 0,03 & 1,00 & 0,34 & - & - \\
\hline
\end{tabular}

A identificação dos fatores de risco para mastite tendo como referência a CCSLT é objetiva e de baixo custo, mas os resultados devem ser interpretados considerando-se as características gerais do rebanho e de procedimentos comuns a todos os animais. Para identificar possíveis fatores de risco para mastite relacionados às características do rebanho, aos procedimentos de manejo e às características individuais dos animais em uma determinada população de bovinos leiteiros ou em estratos dessa população, é necessário obter informações individuais por meio da contagem de células somáticas e/ou exames microbiológicos dos animais.

\section{CONCLUSÕES}

A anti-sepsia antes e após a ordenha, a linha de ordenha, o não fornecimento de alimento durante a ordenha foram identificados como procedimentos que contribuem para evitar alta contagem de células somáticas do rebanho. A utilização de quatro situações diferentes para a análise dos fatores que influenciaram a CCSLT permitiu inferir de forma geral e específica os principais fatores de risco para CCSLT acima de 500.000 células $/ \mathrm{ml} \mathrm{e} 750.000$ células $/ \mathrm{ml}$.

\section{REFERÊNCIAS BIBLIOGRÁFICAS}

AGGER, J.F.; PRIOU, C.; HUDA, A. et al. K. Risk factors for transmission of Streptococcus agalactiae infection between Danish dairy herds: a case control study. Vet. Res., v.25, p.227-234, 1994.

AHL, A.S.; ACREE, J.A.; GIPSON, P.S. et al. Standardization of nomenclature for animal health risk analysis. Rev. Sci. Technol. Off. Intern. Epiz., v.12, p.1045-1053, 1993.

BARKEMA, H.W.; SCHUKKEN, Y.H.; LAM, T.J.G.M. et al. Management practices associated with low, medium, and high somatic cell counts in bulk milk. J. Dairy Sci., v. 81, p.1917-1927, 1998.

BARKEMA, H.W.; VAN DER PLOEG, J.D.; SCHUKKEN, Y.H. et al. Management style and its association with bulk milk somatic cell count and incidence rate of clinical mastitis. J. Dairy Sci., v.82, p.1655-1663, 1999. 
BERRY, E. A.; HILLERTON, J.E. The effect of selective dry cow treatment o new intramammary infections. J. Dairy Sci., v.85, 112-121, 2002.

BRAMLEY A.J.; CULLOR, J.S.; ERSKINE, R.J. et al. Current concepts of bovine mastitis. 4.ed. Wisconsin: National Mastitis Council, 1996. 64p.

BRITO, J.R.F.; BRITO, M.A.V.P.; ARCURI, E.F. Como (re)conhecer e controlar a mastite em rebanhos bovinos. Juiz de Fora: Embrapa Gado de Leite, 2002. 8p. (Circular Técnica 70).

BRITO, M.A.V.P.; BRITO, J.R.F.; VEIGA, V.M.O. et al. Udder infection patterns in hand and machine milked dairy herds under subtropical conditions. In: PANAMERICAN CONGRESS ON MASTITIS CONTROL AND MILK QUALITY, 1., 1998, Merida. Proceedings... Merida, 1998. p.148-151.

CAVAZOS, F. Useful ideas and principles for the implementation of reinforcement programs to keep milkers motivated. In: ANUAL MEETING OF NATIONAL MASTITIS COUNCIL, 42., 2003, Fort Worth. Proceedings... Madison: NMC, 2003. p.77-85.

FRANKENA, K.; GRAAT, E.A.M. Multivariate analysis: logistic regression. In: NOORDHUIZEN, J.P.T.M.; FRANKENA, K.; VAN DER HOOFD, C.M. et al. Apllication of quantitative methods in veterinary epidemiology. 1.ed. Wageningen: Wageningen Pers, 1997. p.135-178.

HUESTON, W.D.; HEIDER, L.E.; HARVEY, W.R. et al. Determinants of high somatic cell count prevalence in dairy herds practicing teat dipping and dry cow therapy and with no evidence of Streptococcus agalactiae on repeated bulk tank milk examination. Prev. Vet. Med., v.9, p.131-142, 1990.

OLIVER, S.P.; LEWIS, M.J.; INGLE, T.L. et al. Prevention of bovine mastitis by a premilking teat disinfectant containing chlorous acid and chlorine dioxide. J. Dairy Sci., v. 76, p.287-292, 1993.

OMORE, A.O.; McDERMOTT, J.J.; ARIMI, S.M. et al. A longitudinal stydy of milk somatic cell counts and bacterial culture from cows on smallholder daity farms in Kiambu District, Kenya. Prev. Vet. Med., v.29, p.77-89, 1996.

OTT, S.L.; NOVAK, P.R. Association of herd productivity and bulk-tank somatic cell counts in US dairy herds in 1996. J. Am. Vet. Med. Assoc., v.218, p.1325-1329, 2001.

PEERLER, E.J.; GREEN, M.J.; FITZPATRICK, J.L. et al. Risk factors associated with clinical mastitis in low somatic cell count British dairy herds. In: SYMPOSIUM OF THE INTERNATIONAL SOCIETY FOR VETERINARY EPIDEMIOLOGY AND ECONOMICS, 9., 2000, Breckenridge. Proceedings... Breckenridge: ISVEE, 2000. 1 CD.

SCHUKKEN, Y.H.; VAN DE GEER, D.; GROMMERS, F.J. et al. Intramammary infections and risk factors for clinical mastitis in herds with low somatic cell counts in bulk milk. Vet. Rec., v.125, p.393-396, 1989.

SPENCER, S.B. Equipamento de ordenha $X$ controle de mastite e qualidade do leite. In: CONGRESSO PANAMERICANO DE QUALIDADE DO LEITE E CONTROLE DE MASTITE, 2., 2002, Ribeirão Preto. Anais... São Paulo: Instituto Fernando Costa, 2002. p.119-148.

STATISTICAL Package for the Social Science. Version 8.0. Chicago: SPSS Inc., 1998.

THRUSFIELD, M.V.; NOORDHUIZEN, J.P.T.M. Current areas of application of epidemiology and perspectives. In: NOORDHUIZEN, J.P.T.M.; FRANKENA, K.; van der HOOFD, C.M. et al. Apllication of quantitative methods in veterinary epidemiology. Wageningen: Wageningen Pers, 1997. p.15-30.

WILSON, D.J.; HELENA, H.D.; GONZALEZ, R.N. et al. Association between management practices, dairy herd characteristics, and somatic cell count of bulk tank milk. J. Am. Vet. Med. Assoc., v.210, p.1499-1502, 1997. 